\title{
Oral health and Candida carriage in socioeconomically disadvantaged US pregnant women
}

Jin Xiao ${ }^{1 *}$ D, Colleen Fogarty ${ }^{2}$, Tong Tong Wu ${ }^{3}$, Naemah Alkhers ${ }^{1}$, Yan Zeng ${ }^{1,4}$, Marie Thomas ${ }^{2}$, Moustafa Youssef ${ }^{1}$, Lin Wang ${ }^{1,5}$, Lauren Cowen ${ }^{2}$, Hossam Abdelsalam ${ }^{1}$ and Anna Nikitkova ${ }^{1}$

\begin{abstract}
Background: Despite the well-documented associations between poor maternal oral health and increased risk for adverse birth outcomes and dental caries in children after birth, prenatal oral health care is under-utilized, especially among the underserved population. In addition, oral Candida has recently been suggested as a potential culprit for children's dental caries, with evident maternal contributions. Therefore, this study aimed to obtain epidemiological data on the oral health and oral Candida carriage in a cohort of underserved US pregnant women, and reveal factors associated with their oral Candida carriage.
\end{abstract}

Methods: Demographic-medical-oral hygiene practice data were collected. Comprehensive oral examination was conducted. Caries status and plaque index were recorded. Oral samples (saliva, plaque and swab) were processed to identify Candida species and Streptococcus mutans by culturing-dependent and -independent methods. Multiple logistic regression analyses were used to identify factors associated with oral Candida carriage and caries severity.

Results: Eighty-two socioeconomically disadvantaged women (48 pregnant and 34 non-pregnant) were enrolled. More pregnant women (79.1\%) had $>=1$ untreated decayed tooth when compared to their non-pregnant counterparts (47.1\%) $(p=0.01)$. The average number of decayed teeth in pregnant and non-pregnant women was 3.9 and $3.1(p>0.05)$. Caries severity was positively associated with race (African American vs. white), plaque index and salivary Candida albicans level. C. albicans was the most predominant/abundant Candida strain, with cheek and tonsil as the most common colonized sites. The detection of C. albicans was 56\%/56\% in saliva and 40\%/ $47 \%$ in plaque of the pregnant and non-pregnant groups, respectively. Study women's oral Candida carriage is positively associated with hypertension $[p=0.03$, odds ratio $=14.47(1.28,163.51)]$, decayed teeth number $[p=0.04$, odds ratio $=1.31(1.01,1.69)]$ and salivary $S$. mutans level $[p=0.03$, odds ratio $=4.80(1.18-19.43)]$.

Conclusions: Socioeconomically disadvantaged US women are in need of improved prenatal oral health, a large proportion of them have untreated decayed teeth and high carriage of oral Candida. Due to the observed significant association between the decayed teeth number and oral Candida carriage, providing oral health care during pregnancy (including limiting decayed teeth) will not only improve women's oral health, but also present as a promising approach to reduce oral Candida carriage in women.

Keywords: Oral health, Pregnancy, Yeast infection, Candida, Dental caries

\footnotetext{
* Correspondence: jin_xiao@urmc.rochester.edu

${ }^{1}$ Eastman Institute for Oral Health, University of Rochester Medical Center,

625 Elmwood Ave, Rochester, USA

Full list of author information is available at the end of the article
}

(c) The Author(s). 2019 Open Access This article is distributed under the terms of the Creative Commons Attribution 4.0 International License (http://creativecommons.org/licenses/by/4.0/), which permits unrestricted use, distribution, and reproduction in any medium, provided you give appropriate credit to the original author(s) and the source, provide a link to the Creative Commons license, and indicate if changes were made. The Creative Commons Public Domain Dedication waiver (http://creativecommons.org/publicdomain/zero/1.0/) applies to the data made available in this article, unless otherwise stated. 


\section{Background}

Oral health during pregnancy is vital to expectant mothers and their children. Poor maternal oral health is known to be associated with increased adverse birth outcomes, particularly preterm and low birth weight deliveries [1, 2]. A systematic review analyzed data from 22 studies and 17,053 participants, and revealed the risk of giving preterm birth among mothers with periodontitis was 1.61 times compared to those without periodontitis $(p<0.001)$; additionally, the risk of delivering low birth weight infants among mothers with periodontitis was 1.65 times as to those without periodontitis $(p<0.001)$ [3]. Furthermore, receiving prenatal periodontal treatment presents potentials to reduce adverse birth outcome. A recent study reanalyzed the data from a previous birth cohort, and suggested that periodontal treatment provided to mothers with mild to moderate periodontal disease before 21 weeks of gestation may prevent preterm births [4].

Besides the association between maternal periodontal diseases and adverse birth outcomes, a strong correlation was also found between maternal carriage of dental caries related microorganisms and an increased risk for dental caries in children [5]. Dental caries is a multifactorial disease with microbial, host genetics, diet, and socio-behavioral determinants [6-9]. Dental caries initiated from the virulent dental biofilms/plaque formed on tooth surfaces [10]. Within the dental biofilms/plaque, oral cariogenic bacteria metabolize dietary carbohydrate; produce acid and initiate demineralization of tooth enamel [11]. Although an enamel remineralization process takes place when the enamel is exposed to salivary calcium, phosphate and fluoride ions, however when the demineralization exceeds the remineralization process, dental caries occur [12]. Understanding the acquisition of cariogenic microbes are vital to the development of improved preventive strategies.

Streptococcus mutans and Lactobacillus species have traditionally been considered the prime microbial risk markers for dental caries [13-19]. Chaffee et al. found the high maternal carriage of both salivary S. mutans and Lactobacilli is associated with nearly doubled children's caries incidence versus low S. mutans and Lactobacilli mothers (cumulative incidence ratio: 1.9; 95\% confidence interval: 1.1, 3.8), after adjusting socio-demographics, feeding and care practices, and maternal dental status [5]. Besides these traditional culprits for dental caries, recent research on the role of Candida species in early childhood caries (ECC) and its synergistic interaction with $S$. mutans, has shed new light on potential fungus-focused approaches to early prediction and subsequent prevention of ECC. Candida species (especially C. albicans) have often been detected at higher levels in the oral cavity of children with ECC, compared to caries free children [19-27], and is positively correlated with caries severity [28]. In a recent meta- analysis, we showed that children with oral C. albicans presented with $>5$ times greater odds of experiencing ECC than children without this yeast strain [29]. More important, we have shown that mothers of the children affected by ECC also have high $C$. albicans carriage (> 80\% detection in both saliva and plaque samples) [28].

Maternal contribution to children's Candida colonization was demonstrated in several studies. The vertical transmission rate from mother to newborns ranges from 14\% typed by electrophoretic karyotyping and restriction endonuclease analysis of genomic DNA with pulsed-field gel electrophoresis, to $41 \%$ typed by DNA fingerprinting using a $C$. albicans strain-specific DNA probe [30, 31]. We further identified that more than $60 \%$ of mother and children with severe ECC aged between 2 to 5 years old shared identical oral Candida strains [28].

Even though the benefits of maintaining good maternal oral health during pregnancy are well demonstrated, many mothers-to-be do not receive timely prenatal oral care [32]. A national survey [33] recently released by a dental insurance company, Cigna, found that $43 \%$ of women have not had a dental checkup while $76 \%$ admitted to suffering from oral health problems (pain, gum bleeding and oral infection) during pregnancy. Our data from a US oral health institute urgent care clinic showed that instead of receiving routine prenatal oral health care, more than $10 \%$ of local socioeconomically disadvantaged expectant mothers sought dental emergency treatment during pregnancy; the provided procedures to expectant mothers ranged from relieving orofacial pain, treating severe periodontal inflammation, treating severe tooth decay and its related maxillofacial infection. Furthermore, prenatal dental care utilization was lower among black women [34], ethnic minorities [35] and women with socioeconomic disadvantages [36]. Thus, oral health represents an important often-neglected heath disparity during pregnancy $[37,38]$.

Understanding the oral health condition of expectant mothers, particularly the ones with socioeconomic disadvantages can help us to design appropriate preventive and treatment strategies to help mothers gain better oral health during pregnancy, and provide further benefits to their children. Additionally, since controlling infants' oral Candida carriage has been raised as a promising strategy in ECC prevention, understanding the factors associated with mother's Candida carriage is essential to prevention of oral Candida colonization in infants. Therefore, this study was conducted to 1) obtain epidemiological data on oral health and oral carriage of Candida species in a group of US pregnant women with socioeconomic disadvantages, in comparison to their non-pregnant counterparts; 2) examine the relationship between demographic, medical and oral health status, and oral Candida carriage in pregnant women. 


\section{Methods}

\section{Study population}

The study protocols were approved by the University of Rochester Research Subject Review Board (RSRB00056870 and RSRB00067191). All participants were informed of the study objectives and protocols, and gave written consent prior to study activities. Pregnant women were sampled from patients visiting the University of Rochester Highland Family Medicine (HFM) or Eastman Institute for Oral Health (EIOH). Control subjects, non-pregnant women, was a convenient sample collected from patients visiting the University of Rochester Eastman Institute for Oral Health. Both clinics, HFM and $\mathrm{EIOH}$, serve a large body of low-income patients, with a range of $40 \%$ African Americans, $40 \%$ White and 20\% others. The status of holding New York state-support medical insurance was used as a filter for the selection of women with socioeconomic disadvantages. The age and socioeconomic status of the subjects were used to match between the pregnant and non-pregnant groups.

\section{Sample size}

We calculated the sample size based on the estimation that $60 \%$ of pregnant women have untreated decayed teeth, compared to $21.8-30.3 \%$ of women in the general population who have untreated decayed teeth, reported by CDC [39]. The average of the reported proportions, $25 \%$, was used for the non-pregnant women group. A ztest with unpooled variance at alpha $=0.05$ gives us a sample size to achieve $80 \%$ power comprised of 28 women in each group, a total of 56 study subjects.

\section{Eligibility}

For the pregnant women group, individual who met for the following inclusion criteria and exclusion criteria were enrolled. For the control group women who are not pregnant, all inclusion and exclusion criteria apply except the items relate to pregnancy. Inclusion criteria included:1) Female, equal or older than 18 years of age. 2) Pregnant with singleton fetus and in her 3rd trimester (time period extending from the 28th week of gestation until delivery). 3) Eligible for New York state-supported medical insurance, which is determined by income level ( $\leq 138 \%$ Federal Poverty Line).

Exclusion criteria included:1) Subjects who have decisional impairment deeming incapable of making an informed decision about her participation in the study. 2) Subjects who received oral and/or systemic antifungal therapy within 90 days of the baseline study visit. 3) Subjects who have severe systemic medical conditions (e.g., HIV infection) that make them prone to yeast infections.
Data collection, examination and sample collection

Data on demographics were self-reported by the study subjects. Data on the medical background and medications were collected through self-reporting and confirmed by electronic medical records. See Additional file 1 for the demographic-medical background. The medical background included: 1) physician-diagnosed systemic diseases, such as hypertension, diabetes, asthma, anxiety, depression, kidney disease, liver disease, etc.; 2) medications that subjects were taking when enrolled in the study; 3) smoking status (Y/N). Data on oral hygiene practice that were collected through a survey form. A comprehensive oral examination (caries score, plaque index and oral candidiasis) was performed by one of three calibrated dentists in a dedicated examination room at the University of Rochester clinics, using standard dental examination equipment, materials and supplies, under portable lighting. Dental caries was scored using decayed, missing and filled teeth (MDFT) according to the codes proposed by WHO Oral health surveys - basic methods, 4th edition, 1997 [40]. Dental plaque was assessed using the plaque index as described by Löe [41]. Oral mucosa was evaluated using oral candidiasis clinical diagnosis criteria and defined as pseudomembranous/erythematous forms [42]. Inter- and intra-examiner agreement for the evaluated criteria was calculated by Kappa statistics, and exceeded $83 \%$ at the calibration.

The whole non-stimulated saliva samples were collected by spitting into a sterilized $50 \mathrm{ml}$ centrifuge tube. Approximately $1 \mathrm{ml}$ of saliva was collected for each subject. Supragingival plaque from the whole dentition (all surfaces of all teeth) was collected using a sterilized periodontal scaler [28]. The plaque samples were suspended in $1 \mathrm{ml}$ of a $0.9 \%$ sodium chloride solution in a sterilized Eppendorf tube. To examine the mucosal Candida infection site, for pregnant women with positive detection of salivary or plaque C. albicans, additional mucosal swab samples were collected from cheek mucosa, labial mucosa, dorsal surface of tongue, hard palate, and tonsils using FlocqSwabs (Copan Diagnostics, CA, USA) at the next study visit.

Vaginal C. albicans test was prescribed for 33 pregnant women by their physicians within a window of 12 months before entering our study; available vaginal $C$. albicans data was obtained through the electronic medical records.

\section{Quantification and identification of Candida spp. and S. mutans}

After the sample collection, the clinical samples (saliva/ plaque/swab) were stored on ice and transferred to the lab located at the University of Rochester Center for Oral Biology within $2 \mathrm{~h}$ for laboratory testing. The saliva and plaque sample were gently vortexed and sonicated 
to break down the aggregation before plating. The sonication cycle was repeated three times, with $10 \mathrm{sec}$ sonication and $30 \mathrm{sec}$ rest on ice. $\mathrm{BBL}^{\mathrm{ma}}$ CHROMagar ${ }^{\mathrm{mm}}$ Candida (BD, Sparks, MD, USA) was used to isolate $C$. albicans by incubating at $37^{\circ} \mathrm{C}$ for $48 \mathrm{~h}$. This medium permits presumptive identification of several clinically important Candida species including C. albicans, C. krusei, C. galabrata, C. dubliniensis, etc., based on the colony color and morphology [43]. CHROMagar ${ }^{\mathrm{Tm}}$ Candida culturing medium has shown high $C$. albicans detection sensitivity (98.6\%) and specificity (98.8\%) [42]. S. mutans was isolated using Mitis Salivarius with Bacitracin selective medium by incubating at $37{ }^{\circ} \mathrm{C}$ for $48 \mathrm{~h}$ and identified by colony morphology [44]. Colonies of Candida spp. and S. mutans on each plate were counted and recorded as colony forming unit (CFU). Additionally, $C$. albicans and S. mutans were further identified using colony polymerase chain reaction method. The probes used for $C$. albicans were forward primer 5'CGATT CAGGGGAGGTAGTGAC3' and reverse primer 5'GG TTCGCCATAAATGGCTACCAG 3'. The probes used for $S$. mutans were forward primer $5^{\prime}$ TCGCGAAAAA GATAAACAAACA 3' and reverse primer 5' GCCCCT 'TCACAGTTGGTTAG 3' [45].

\section{Data analysis}

During data analysis, women in the study were grouped based on their pregnancy status and oral Candida status. The characteristics of the two groups (pregnant vs. nonpregnant; oral Candida positive vs. oral Candida negative) were compared using t-test for continuous data and Chi-square or Fisher's exact tests for categorical data.

Table 1 Demographic, medical and oral condition characteristics of study subjects by pregnancy status

\begin{tabular}{|c|c|c|c|c|}
\hline \multicolumn{2}{|l|}{ Categories } & \multirow{2}{*}{$\begin{array}{l}\text { Non-Pregnant } \\
(n=34)\end{array}$} & \multirow{2}{*}{$\begin{array}{l}\text { Pregnant } \\
(n=48)\end{array}$} & \multirow{2}{*}{$\begin{array}{l}p \text {-value } \\
0.34\end{array}$} \\
\hline Age (year) & & & & \\
\hline \multirow[t]{4}{*}{ Race } & African American & $24 \%(8)$ & $52 \%(25)$ & \multirow[t]{4}{*}{$<0.001$} \\
\hline & White & $53 \%(18)$ & $17 \%(8)$ & \\
\hline & Asian & $21 \%(7)$ & $8 \%(4)$ & \\
\hline & Others & $3 \%(1)$ & $23 \%(11)$ & \\
\hline \multirow[t]{2}{*}{ Ethnicity } & Hispanic & $18 \%(6)$ & $10 \%(5)$ & \multirow[t]{2}{*}{0.34} \\
\hline & Non-Hispanic & $82 \%(28)$ & $93 \%(43)$ & \\
\hline \multicolumn{2}{|c|}{ Use of antibiotics $>1$ months in the past 6 months (Yes) } & $0 \%(0)$ & $4 \%(2)$ & 0.23 \\
\hline \multicolumn{2}{|l|}{ Diabetes (Yes) } & $0 \%(0)$ & $8 \%(4)$ & 0.08 \\
\hline \multicolumn{2}{|l|}{ Asthma (Yes) } & $9 \%(3)$ & $8 \%(4)$ & 0.94 \\
\hline \multicolumn{2}{|l|}{ Hypertension (Yes) } & $9 \%(3)$ & $17 \%(8)$ & 0.31 \\
\hline \multicolumn{2}{|c|}{ Anxiety and/or depression (Yes) } & $9 \%(3)$ & $19 \%(9)$ & 0.21 \\
\hline \multicolumn{2}{|l|}{ Smoking (Yes) } & $18 \%(6)$ & $13 \%(6)$ & 0.52 \\
\hline \multirow[t]{3}{*}{ Tooth brushing } & Twice/daily & $82 \%(28)$ & $63 \%(30)$ & \multirow[t]{3}{*}{0.11} \\
\hline & Once/daily & $15 \%(5)$ & $35 \%(17)$ & \\
\hline & <one/daily & $3 \%(1)$ & $2 \%(1)$ & \\
\hline \multicolumn{2}{|l|}{ Plaque index } & $1.5 \pm 0.9$ & $1.7 \pm 0.6$ & 0.002 \\
\hline \multicolumn{2}{|c|}{ Untreated decayed teeth percentage } & $47.1 \%(18)$ & $79.1 \%(38)$ & 0.01 \\
\hline \multicolumn{2}{|l|}{ Decayed teeth number (DT) } & $3.1 \pm 4.8$ & $3.9 \pm 3.8$ & 0.33 \\
\hline \multicolumn{2}{|c|}{ Decayed, missing, filled teeth number (DMFT) } & $6.9 \pm 6.4$ & $7.5 \pm 4.5$ & 0.09 \\
\hline \multicolumn{2}{|c|}{ Salivary S. mutans carriage $\left(10^{6} \mathrm{CFU} / \mathrm{ml}\right)$} & $2.1 \pm 4.5$ & $1.3 \pm 2.1$ & 0.12 \\
\hline \multirow[t]{3}{*}{ Salivary S. mutans carriage } & No carriage & $9 \%(3)$ & $0 \%(0)$ & \multirow[t]{3}{*}{0.01} \\
\hline & $1-10^{5} \mathrm{CFU} / \mathrm{ml}$ & $38 \%(13)$ & $19 \%(9)$ & \\
\hline & $>10^{5} \mathrm{CFU} / \mathrm{ml}$ & $53 \%(18)$ & $81 \%(39)$ & \\
\hline \multicolumn{2}{|c|}{ Salivary C. albicans carriage $\left(10^{3} \mathrm{CFU} / \mathrm{ml}\right)$} & $1.3 \pm 2.6$ & $1.4 \pm 5.5$ & 0.66 \\
\hline \multirow[t]{3}{*}{ Salivary C. albicans carriage } & No carriage & $44 \%(15)$ & $44 \%(21)$ & \multirow[t]{3}{*}{0.63} \\
\hline & $1-400$ CFU/ml & $24 \%(8)$ & $33 \%(16)$ & \\
\hline & $>400 \mathrm{CFU} / \mathrm{ml}$ & $32 \%(11)$ & $23 \%(11)$ & \\
\hline
\end{tabular}


One-way ANOVA and Turkey test was used to compare the $C$. albicans carriage between swab samples taken from different mucosal sites. Mann-Whitney U Test was performed to compare the difference of decayed teeth number in relation to other binary variables including pregnancy, smoking, inhaler use for asthma, and ethnicity (Hispanic and non-Hispanic). Spearman's rank was used to measure the correlation between variables (decayed teeth number, age, plaque index, salivary/ plaque $C$. albicans and S. mutans carriage). Cohen's kappa was calculated to test the agreement between oral and vaginal $C$. albicans detection. A cumulative logistic regression analysis was used to test variables associated with caries severity among study subjects. The caries severity was grouped into three levels: 0 (no decay), 1 ( $<=3$ decayed teeth) and 2 ( $>3$ decayed teeth). Multiple logistic regression analyses were used to identify predictors of Candida carriage among study subjects. Estimated odds ratios (OR) and 95\% confidence intervals (CIs) were calculated for the variables that were statistically significant. The variables in the regression analyses were selected in multiple steps. We first selected a list of variables from the dental literature which might be potentially correlated with the outcome variables. Then, for the covariates like age, race, tooth brushing frequency, even though they have high $p$-values and are insignificant in the model, we still retained them in the model. Other variables, especially clinical characteristics, such as diabetes, asthma, hypertension, were selected based on $p$-values. We used a cut-off of 0.2 for the inclusion of those variables. All statistical tests were two-sided with a significance level of $5 \%$. SAS were used for all statistical analyses.

\section{Results}

Oral health and Candida carriage among pregnant and non-pregnant women

A total of 48 eligible pregnant women and 34 nonpregnant women were enrolled in this study. None of the expectant mothers reported having dental exams since their pregnancy. Characteristics of the study population are shown in Table 1. No statistical differences
(A)

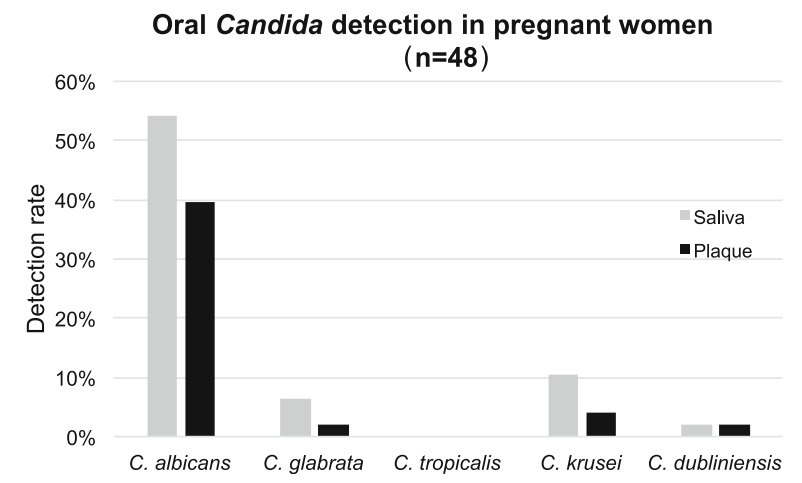

(C)

$$
1.60 \mathrm{E}+05
$$

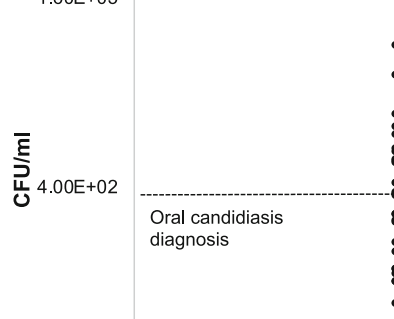

$1.00 \mathrm{E}+00$
C. albicans carriage in pregnant women

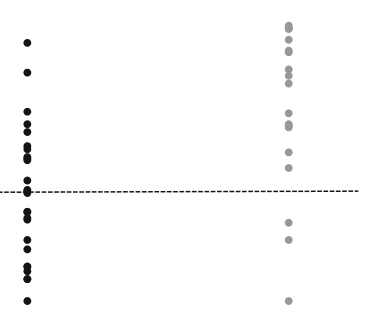

Saliva
(B)

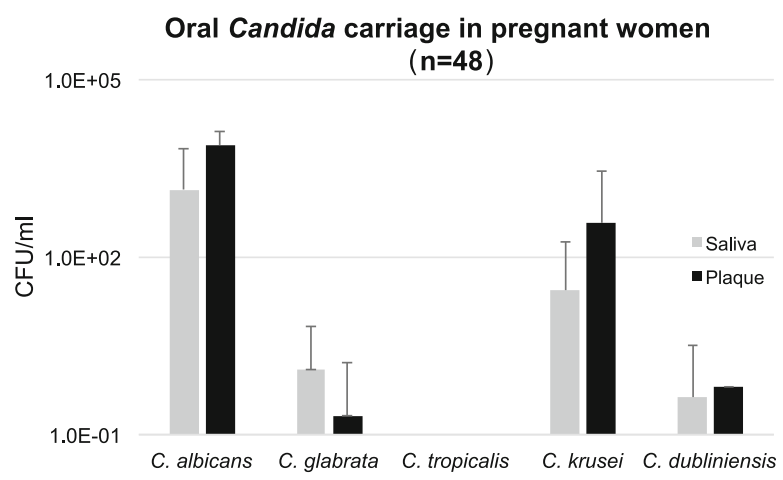

(D)

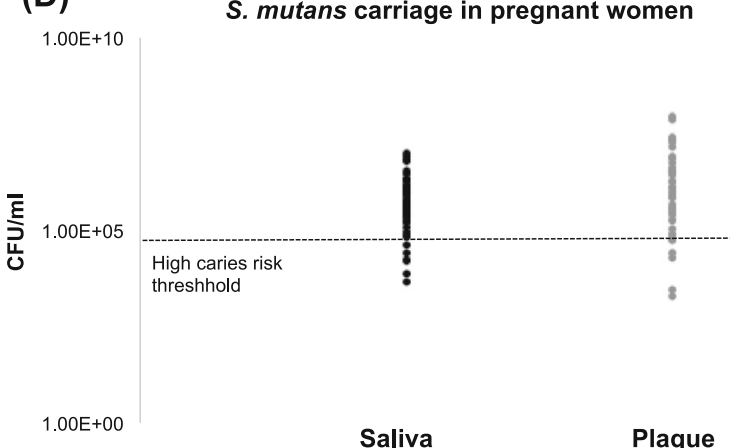

Fig. 1 Oral Candida status in pregnant women; a Oral (saliva and plaque) Candida species detection in pregnant women. b Candida species carriage in the saliva and plaque of pregnant women. c Carriage plot of C. albicans in pregnant women with positive detection, a horizontal line indicating $400 \mathrm{CFU} / \mathrm{ml}$ is draw in the plot, which is an oral candidiasis criteria based on the salivary candida CFU established by Epstein et al [46]. d Carriage plot of S. mutans in pregnant women with positive detection, a horizontal line indicating $1.0 \times 10^{5} \mathrm{CFU} / \mathrm{ml}$ is draw in the plot, which indicates a threshold of high risk for dental caries 
was detected between the pregnant and non-pregnant groups in terms of age, ethnicity, medical background, smoking status, tooth brushing habit, decayed teeth, decayed/missing/filled teeth, and salivary $C$. albicans carriage $(p>0.05)$. Pregnant women's plaque index and salivary $S$. mutans carriage was higher than nonpregnant women's $(p<0.05)$. Strikingly, $79.1 \%$ of pregnant women and $47.1 \%$ of non-pregnant women had at least 1 untreated decayed tooth $(p=0.01)$; the average number of decayed teeth (DT) of the study pregnant women and non-pregnant women are $3.9 \pm 3.8$ and $3.1 \pm$ 4.8; no difference regarding the decayed teeth number was seen between pregnant and non-pregnant groups $(p>$ 0.05). Moreover, the average number of DMFT of the study pregnant women and non-pregnant women are $6.9 \pm 6.4$ and $7.5 \pm 4.5(p=0.09)$.

Prevalence of oral Candida carriage is shown in Fig. 1 (pregnant women) and Additional file 2: Figure S1 (nonpregnant women). The overall Candida detection rates were similar: 56 and $56 \%$ in saliva, and 40 and $47 \%$ in plaque, in the pregnant and non-pregnant groups, respectively. C. albicans was the most predominant and abundant species found in Candida carriers of both groups (Fig. 1a, b, Additional file 2: Figure S1A and B). C. glabrata, C. krusei, C. tropicalis and C. dunliniensis were also detected among study subjects, with detection rates ranging from 3 to $11 \%$.

Intriguingly, none of the study subjects were diagnosed as oral candidiasis upon clinical examination based on clinical diagnostic criteria, however when we plot the amount of salivary C. albicans carried in pregnant women group (Fig. 1c), we found more than $50 \%$ of the pregnant women could be diagnosed as oral candidiasis based on the salivary Candida CFU established by Epstein et al [46]. Moreover, 81\% of pregnant subjects carried $>10^{5} \mathrm{CFU} / \mathrm{ml}$ of $S$. mutans in their saliva, setting them in the population who are at high risk for dental caries, shown in Fig. 1d.

(A)

Site-specific $C$. albicans detection in pregnant women $(n=24)$

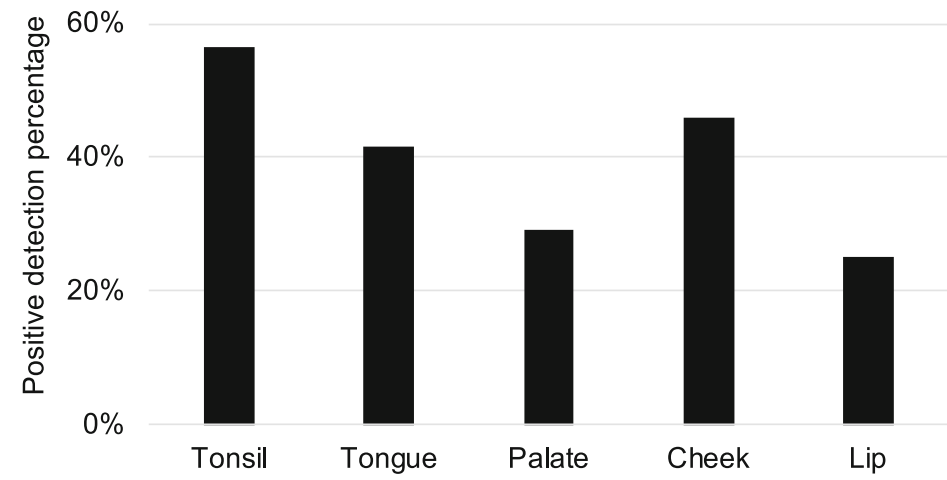

(B) Site-specific C. albicans carriage in pregnant women $(n=24)$

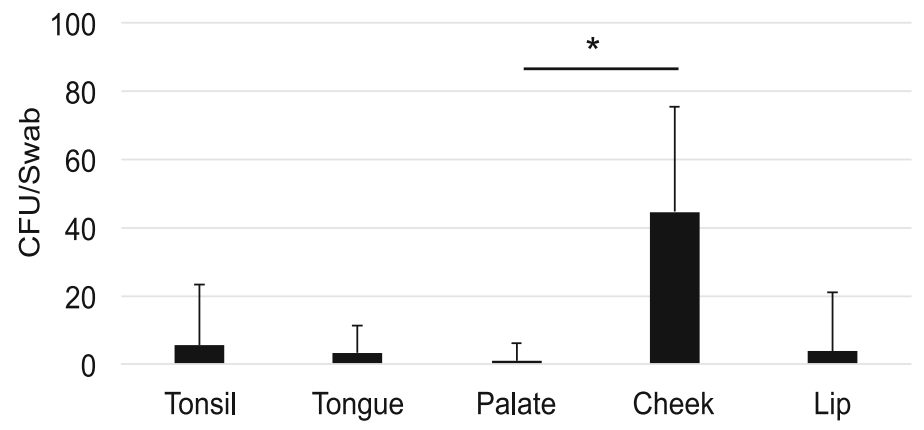

$\left({ }^{*} \mathrm{p}<0.05\right)$

Fig. 2 Oral C. albicans site-specific detection in pregnant women, The detection (a) and carriage (b) of C. albicans in different oral cavity sites of pregnant women were shown. Tonsil present as the most popular detection sites, followed by Cheek, tongue, hard palate and inner lip. Cheek has the most abundant carriage for C. albicans, with a statistically significant difference between the cheek and palate sites 
Oral mucosal site-specific $C$. albicans detection in pregnant women

Among 24 pregnant women who had positive C. albicans detection, we further determined the oral mucosal sites for C. albicans detection, results are seen in Fig. 2 . Tonsil (57\%) was the most prevalent site for C. albicans detection, followed by cheek (46\%), tongue (42\%), hard palate $(29 \%)$ and inner side of the upper and lower lips (25\%) (Fig. 2a). C. albicans was more abundant on the cheek mucosal surfaces when compared to the palatal mucosal surfaces, with a mean value of $13.21 \pm 30.66$ vs. $0.92 \pm 5.24 \mathrm{CFU} / \mathrm{swab}(p<0.05)$, shown in Fig. $2 \mathrm{~b}$. No quantitative differences were found between other mucosal sites $(p>0.05)$.

\section{Comparison between oral and vaginal C. albicans detection in pregnant women}

A comparison was made between oral and vaginal $C$. albicans detection among these 33 pregnant women (see Fig. 3). Specifically, $58 \%$ of pregnant women had consistent oral and vaginal C. albicans findings; $21 \%$ of the pregnant women had positive C. albicans detection from both oral and vaginal sites; $37 \%$ of pregnant women had negative C. albicans detection from both oral and vaginal sites. Whereas, $42 \%$ of the pregnant women had disagreement between the oral and vaginal C. albicans

\section{Comparison between oral and vaginal C. albicans detection among pregnant women $(n=33)$}

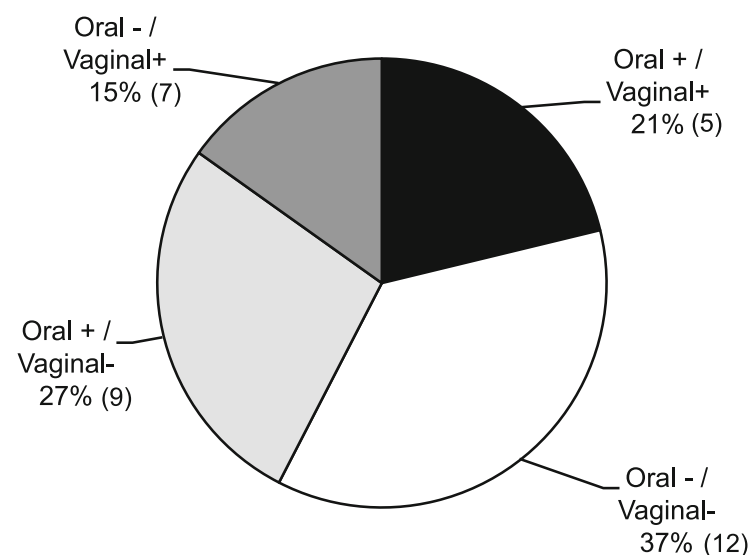

Fig. 3 Comparison between oral and vaginal C. albicans detection among pregnant women, A comparison was made between oral and vaginal $C$. albicans detection among 33 study pregnant women. Nineteen (58\%) pregnant women had consistent oral and vaginal $C$. albicans findings among which 7 (21\%) pregnant women had positive C. albicans detection from both oral and vaginal sites and 12 (37\%) had negative detection from both sites. Fourteen (42\%) pregnant women have positive detection in only one site. Cohen's kappa 0.144 (95\% C.I. $[-0.196,0.485])$ shows a slight agreement between oral and vaginal C. albicans detection detection; $27 \%$ had positive oral C. albicans detection but absent for vaginal C. albicans; $15 \%$ had negative oral C. albicans detection but positive vaginal C. albicans detection. Cohen's kappa 0.144 (95\% C.I. [- 0.196, 0.485]) showed a slight agreement between oral and vaginal $C$. albicans detection.

\section{Factors associated with decayed teeth number in in women with socioeconomic disadvantages}

The decayed teeth number significantly differed between these groups: ethnicity $(p=0.026)$ and inhaler use for asthma $(p=0.047)$; The decayed teeth number was marginally different between pregnant and non-pregnant groups $(p=0.051)$; no difference were detected between smoking and non-smoking groups $(p=0.27)$. The correlation between variables tested by Spearman's rank is shown in Table 2. Decayed teeth number was significantly correlated with plaque index, salivary and plaque $S$. mutans level, and salivary and plaque $C$. albicans level. To analyze factors associated with caries severity in socioeconomically disadvantaged women, a cumulative logistic regression model was used. The factors input into the analysis were age, race, ethnicity, pregnancy, smoking, tooth brushing frequency, plaque index, salivary Candida level and salivary S. mutans level. Among all the factors, caries severity was positively associated with race (African American vs. White, $p=0.04$, adjusted $\mathrm{OR}=4.22,95 \%$ $\mathrm{CI}=1.07-16.57)$, plaque index $(p=0.001$, adjusted $\mathrm{OR}=$ 4.37, $95 \% \mathrm{CI}=1.79-10.69)$ and salivary $C$. albicans carriage $(p=0.04$, adjusted $\mathrm{OR}=1.47,95 \% \mathrm{CI}=1.02-2.11$ ), detailed in Table 3.

Factors associated with oral C. albicans carriage in women with socioeconomic disadvantages

To analyze the factors associated with oral Candida carriage in socioeconomically disadvantaged women, we further grouped all study women (both pregnant and non-pregnant) into two groups based on the C. albicans status - positive and negative groups. Characteristics of the study population in two groups are shown in Table 4. There were no differences $(p>0.05)$ between C. albicans positive and $C$. albicans negative group in terms of age, race, ethnicity, medical background, tooth brushing habit, and plaque index. More smokers were found in women with positive oral $C$. albicans detection $(p=0.04)$. Furthermore, higher percentage of having untreated decayed teeth, higher number of decayed teeth, higher number of decayed/missing/filled teeth, and higher carriage of salivary $S$. mutans were all found in the women with positive $C$. albicans detection $(p<0.05)$.

Through multivariate logistic regression analysis (results shown in Table 5), the prevalence of oral C. albicans in women with socioeconomic disadvantages was significantly associated with hypertension condition $(p=$ 
Table 2 Spearman's rank correlation between variables

\begin{tabular}{|c|c|c|c|c|c|c|c|}
\hline & DT & Age & Plaque index & Salivary Ca CFU & Salivary Sm CFU & Plaque Ca CFU & Plaque Sm CFU \\
\hline DT & 1 & & & & & & \\
\hline Age & -0.14 & 1 & & & & & \\
\hline Plaque index & $0.44^{* * *}$ & -0.07 & 1 & & & & \\
\hline Salivary Ca CFU & $0.38^{* * *}$ & -0.02 & 0.15 & 1 & & & \\
\hline Salivary Sm CFU & $0.40^{* * *}$ & -0.08 & $0.32^{* *}$ & $0.37^{* *}$ & 1 & & \\
\hline Plaque Ca CFU & $0.35^{* *}$ & -0.04 & 0.14 & $0.075^{* * *}$ & $0.035^{* *}$ & 1 & \\
\hline Plaque Sm CFU & $0.36^{* *}$ & -0.11 & $0.44^{* * *}$ & $0.33^{* *}$ & $0.72^{* * *}$ & $0.38^{* * *}$ & 1 \\
\hline
\end{tabular}

DT Decayed teeth number

Ca C. albicans

Sm S. mutans

CFU Colony forming unit

**Correlation is significant at the 0.01 level (2-tailed)

***Correlation is significant at the $<0.001$ level (2-tailed)

0.03, adjusted $\mathrm{OR}=14.47,95 \% \mathrm{CI}=1.28-163.51$ ), higher decayed teeth $(p=0.04$, adjusted $\mathrm{OR}=1.31,95 \% \mathrm{CI}=$ $1.01-1.69)$ and higher salivary $S$. mutans level $(p=0.03$, adjusted $\mathrm{OR}=4.80,95 \% \mathrm{CI}=1.18-19.43)$. Other demographic, medical background, and oral hygiene practice characteristics were not associated with the prevalence of oral C. albicans in women with socioeconomic disadvantages, including pregnancy status.

\section{Discussion}

Importantly, our study results indicate unmet oral health needs among US women with socioeconomic disadvantages, especially those who are pregnant. Upon examining the oral condition and Candida carriage among 82
US women with low socioeconomic status determined by their eligibility for state-support health insurance, a strikingly fact surfaced is that $79.1 \%$ of pregnant women had at least one untreated decayed tooth, with an average of 3.9 untreated decayed teeth per person. Based on the 2011-2014 CDC survey, 30.3\% of women aged between 20 and 44 had untreated dental caries [39]. The caries rate in the study expectant mothers is significantly higher than the general US population. Untreated oral diseases among pregnant women with low socioeconomic status have been identified in the other states of the US as well. An interdisciplinary community-based oral health program in Florida US reviewed the dental encounter records of 180 underserved pregnant women

Table 3 Factors associated with caries severity in women with socioeconomic disadvantages

\begin{tabular}{|c|c|c|c|c|c|c|c|c|}
\hline \multirow{2}{*}{\multicolumn{2}{|c|}{ Variables }} & \multirow[t]{2}{*}{ Estimate } & \multirow{2}{*}{$\begin{array}{l}\text { Standard } \\
\text { Error }\end{array}$} & \multirow{2}{*}{$\begin{array}{l}\text { Wald } \\
\text { Chisq }\end{array}$} & \multirow[t]{2}{*}{$p$-value } & \multirow{2}{*}{$\begin{array}{l}\text { Odds } \\
\text { Ratio }\end{array}$} & \multicolumn{2}{|c|}{ 95\% confidence interval } \\
\hline & & & & & & & Lower & Upper \\
\hline Age & & 0.003 & 0.04 & 0.003 & 0.95 & 1.00 & 0.92 & 1.10 \\
\hline \multirow[t]{3}{*}{ Race } & African American vs. White & 1.44 & 0.70 & 4.25 & 0.04 & 4.21 & 1.07 & 16.57 \\
\hline & Asian vs. White & -1.03 & 0.94 & 1.22 & 0.27 & 0.36 & 0.06 & 2.23 \\
\hline & Other vs. White & 0.15 & 0.90 & 0.03 & 0.87 & 1.16 & 0.20 & 6.82 \\
\hline \multicolumn{2}{|c|}{ Ethnicity (Non-Hispanic vs. Hispanic) } & 1.19 & 0.93 & 1.65 & 0.20 & 3.28 & 0.54 & 20.11 \\
\hline \multicolumn{2}{|c|}{ Pregnancy } & 0.57 & 0.63 & 0.82 & 0.37 & 1.77 & 0.51 & 6.15 \\
\hline \multicolumn{2}{|c|}{ Smoking } & -0.70 & 0.84 & 0.69 & 0.41 & 0.50 & 0.10 & 2.60 \\
\hline \multicolumn{2}{|c|}{ Tooth brushing frequency } & 0.25 & 0.55 & 0.20 & 0.65 & 1.28 & 0.44 & 3.73 \\
\hline \multicolumn{2}{|c|}{ Plaque index } & 1.47 & 0.46 & 10.42 & 0.001 & 4.37 & 1.79 & 10.70 \\
\hline \multicolumn{2}{|c|}{ Salivary Ca CFU/1000 per ml } & 0.38 & 0.19 & 4.27 & 0.04 & 1.47 & 1.02 & 2.11 \\
\hline \multicolumn{2}{|c|}{ Salivary S. mutans CFU/100000 per ml } & 0.14 & 0.10 & 1.84 & 0.17 & 1.15 & 0.94 & 1.40 \\
\hline
\end{tabular}

A cumulative logistic regression was used to test variables associated with caries severity in women with socioeconomic disadvantages. The caries severity was grouped into three levels: 0 (no decay), 1 ( $<=3$ decayed teeth) and 2 ( $>3$ decayed teeth)

Ca C. albicans

Sm S. mutans

CFU Colony Forming Unit 
Table 4 Demographic, medical and oral condition characteristics of study subjects by Candida status

\begin{tabular}{|c|c|c|c|c|}
\hline \multicolumn{2}{|l|}{ Categories } & \multirow{2}{*}{$\begin{array}{l}\text { C. albicans positive } \\
(n=46) \\
29.3 \pm 5.8\end{array}$} & \multirow{2}{*}{$\begin{array}{l}\text { C. albicans negative } \\
(n=36) \\
28.8 \pm 6.9\end{array}$} & \multirow{2}{*}{$\frac{p \text {-value }}{0.16}$} \\
\hline Age (year) & & & & \\
\hline \multirow[t]{4}{*}{ Race } & African American & $41 \%(19)$ & $39 \%(14)$ & \multirow[t]{4}{*}{0.80} \\
\hline & White & $35 \%(16)$ & $27 \%(10)$ & \\
\hline & Asian & $11 \%(5)$ & $17 \%(6)$ & \\
\hline & Others & $13 \%(6)$ & $17 \%(6)$ & \\
\hline \multirow[t]{2}{*}{ Ethnicity } & Hispanic & $13 \%(6)$ & $14 \%(5)$ & \multirow[t]{2}{*}{0.91} \\
\hline & Non-Hispanic & $87 \%(40)$ & $86 \%(31)$ & \\
\hline \multicolumn{2}{|c|}{ Use of antibiotics $>1$ months in the past 6 months (Yes) } & $0 \%(0)$ & $6 \%(2)$ & 0.11 \\
\hline \multicolumn{2}{|l|}{ Pregnancy (Yes) } & $56 \%(26)$ & $61 \%(22)$ & 0.68 \\
\hline \multicolumn{2}{|l|}{ Diabetes (Yes) } & $4 \%(2)$ & $6 \%(2)$ & 0.80 \\
\hline \multicolumn{2}{|l|}{ Asthma (Yes) } & $9 \%(4)$ & $8 \%(3)$ & 0.95 \\
\hline \multicolumn{2}{|l|}{ Hypertension (Yes) } & $20 \%(9)$ & $6 \%(2)$ & 0.07 \\
\hline \multicolumn{2}{|c|}{ Anxiety and/or depression (Yes) } & $20 \%(9)$ & $8 \%(3)$ & 0.15 \\
\hline \multicolumn{2}{|l|}{ Smoking (Yes) } & $22 \%(10)$ & $6 \%(2)$ & 0.04 \\
\hline \multirow[t]{3}{*}{ Tooth brushing } & Twice/daily & $68 \%(31)$ & $75 \%(27)$ & \multirow[t]{3}{*}{0.40} \\
\hline & Once/daily & $28 \%(13)$ & $25 \%(9)$ & \\
\hline & $<$ Once/daily & $4 \%(2)$ & $0 \%(0)$ & \\
\hline \multicolumn{2}{|l|}{ Plaque index } & $1.7 \pm 0.7$ & $1.5 \pm 0.7$ & 0.89 \\
\hline \multicolumn{2}{|c|}{ Untreated decayed teeth percentage } & $80.0 \%(37)$ & $53 \%(19)$ & 0.008 \\
\hline \multicolumn{2}{|l|}{ Decayed teeth number } & $5.0 \pm 4.8$ & $1.8 \pm 2.3$ & $<0.001$ \\
\hline \multicolumn{2}{|c|}{ Decayed, missing, filled teeth number } & $8.5 \pm 6.0$ & $5.5 \pm 3.7$ & 0.016 \\
\hline \multicolumn{2}{|c|}{ Salivary S. mutans carriage $\left(10^{6} \mathrm{CFU} / \mathrm{ml}\right)$} & $2.1 \pm 4.0$ & $1.0 \pm 2.1$ & 0.046 \\
\hline \multirow[t]{3}{*}{ Salivary S. mutans carriage } & No carriage & $0 \%(0)$ & $11 \%(3)$ & \multirow[t]{3}{*}{0.02} \\
\hline & $1-10^{5} \mathrm{CFU} / \mathrm{ml}$ & $21 \%(8)$ & $30 \%(8)$ & \\
\hline & $>10^{5} \mathrm{CFU} / \mathrm{ml}$ & $79(30)$ & $59 \%(16)$ & \\
\hline \multicolumn{2}{|c|}{ Salivary C. albicans carriage $\left(10^{3} \mathrm{CFU} / \mathrm{ml}\right)$} & $2.4 \pm 5.8$ & 0 & NA \\
\hline \multirow[t]{3}{*}{ Salivary C. albicans carriage } & No carriage & $0 \%(0)$ & $100 \%(36)$ & \multirow[t]{3}{*}{ NA } \\
\hline & $1-400 \mathrm{CFU} / \mathrm{ml}$ & $52 \%(24)$ & $0 \%(0)$ & \\
\hline & $>400 \mathrm{CFU} / \mathrm{ml}$ & $47 \%(22)$ & $0 \%(0)$ & \\
\hline
\end{tabular}

in a Women, Infant, Children (WIC) program, and found $71.2 \%$ of the pregnant women had unmet dental care needs [47].

Second, we revealed a high oral Candida detection rate and carriage among the study women, $56 \%$ in pregnant and non-pregnant women, compared to a lower detection rate in healthy individuals $(16-49 \%)[48,49]$. The average salivary Candida carriage was $1.4 \times 10^{3}$ $\mathrm{CFU} / \mathrm{ml}$ in pregnant women. Intriguingly, although none of the pregnant women presented clinical manifestation of oral candidiasis, more than $50 \%$ of them could be diagnosed as oral candidiasis based on the salivary Candida CFU established by Epstein et al [46], 400 CFU/ml in saliva. Our study results also indicate that with the tonsil being the most popular Candida detection site in the oral cavity, a combination of gauging and swishing oral antifungal rinse might provide better outcomes in treating oral candidiasis.

Third, upon examining the association between pregnancy and oral Candida, we found that pregnancy status is not significantly associated with Candida detection among the study population. This resonates with a previous study, in which pregnancy and diabetes independently did not influence the prevalence of fungi in the oral cavity and rectum of pregnant women [50]. While some efforts have been made to elucidate mechanisms by which pregnancy leads to changes in the composition of the oral microorganisms, the pathways remain unclear. The progesterone and estrogen have been suggested to affect the microbiota during pregnancy, but these effects have not been adequately demonstrated nor directly proven, other than the finding that estrogens 
Table 5 Factors associated with salivary Candida detection in women with socioeconomic disadvantages

\begin{tabular}{|c|c|c|c|c|c|c|c|c|}
\hline \multirow{2}{*}{\multicolumn{2}{|c|}{ Variables }} & \multirow[t]{2}{*}{ Estimate } & \multirow{2}{*}{$\begin{array}{l}\text { Standard } \\
\text { Error }\end{array}$} & \multirow{2}{*}{$\begin{array}{l}\text { Wald } \\
\text { ChiSq }\end{array}$} & \multirow{2}{*}{$\begin{array}{l}p- \\
\text { value }\end{array}$} & \multirow{2}{*}{$\begin{array}{l}\text { Odds } \\
\text { Ratio }\end{array}$} & \multicolumn{2}{|c|}{ 95\% confidence interval } \\
\hline & & & & & & & Lower & Upper \\
\hline Age & & -0.03 & 0.06 & 0.25 & 0.61 & 0.97 & 0.87 & 1.09 \\
\hline \multirow[t]{3}{*}{ Race } & African American vs. others & 0.48 & 1.04 & 0.21 & 0.64 & 1.62 & 0.21 & 12.38 \\
\hline & White vs. others & -0.31 & 1.04 & 0.08 & 0.77 & 0.74 & 1.00 & 5.62 \\
\hline & Asian vs. others & 0.58 & 1.26 & 0.21 & 0.65 & 1.78 & 0.15 & 20.95 \\
\hline \multicolumn{2}{|c|}{ Ethnicity (Non-Hispanic vs. Hispanic) } & -0.50 & 1.18 & 0.18 & 0.68 & 0.61 & 0.06 & 6.13 \\
\hline \multicolumn{2}{|c|}{ Diabetes } & 2.19 & 1.67 & 1.73 & 0.19 & 0.112 & 0.00 & 2.93 \\
\hline \multicolumn{2}{|c|}{ Asthma } & 0.68 & 1.07 & 0.40 & 0.53 & 1.97 & 0.24 & 16.13 \\
\hline \multicolumn{2}{|c|}{ Emotional disorder } & 0.94 & 1.00 & 0.88 & 0.35 & 2.56 & 0.36 & 18.12 \\
\hline \multicolumn{2}{|c|}{ Pregnancy } & -1.18 & 0.82 & 2.07 & 0.15 & 0.31 & 0.06 & 1.54 \\
\hline \multicolumn{2}{|c|}{ Hypertension } & 2.67 & 1.24 & 4.67 & 0.03 & 14.47 & 1.28 & 163.51 \\
\hline \multicolumn{2}{|c|}{ Smoking } & 1.14 & 1.02 & 1.25 & 0.26 & 3.12 & 0.42 & 22.95 \\
\hline \multicolumn{2}{|c|}{ Tooth brushing frequency } & 0.66 & 0.72 & 0.84 & 0.36 & 1.93 & 0.47 & 7.87 \\
\hline \multicolumn{2}{|c|}{ Plaque index } & -0.36 & 0.51 & 0.50 & 0.48 & 0.70 & 0.26 & 1.89 \\
\hline \multicolumn{2}{|c|}{ Decayed teeth } & 0.27 & 0.13 & 4.23 & 0.04 & 1.31 & 1.01 & 1.69 \\
\hline \multicolumn{2}{|c|}{ DMFT (Decayed, Missing, Filled teeth) } & 0.09 & 0.09 & 0.86 & 0.35 & 1.09 & 0.91 & 1.31 \\
\hline \multicolumn{2}{|c|}{ Salivary S. mutans level } & 1.57 & 0.71 & 4.82 & 0.03 & 4.80 & 1.18 & 19.43 \\
\hline
\end{tabular}

Logistic regression model for was used to estimate the Maximum Likelihood and Odds Ratio of variables associated with the saliva Candida detection (yes or no). Hypertension, decayed teeth number and salivary S. mutans carriage level is significantly associated with oral Candida detection in women with socioeconomic disadvantages

enhance Candida infections [51, 52]. It is likely that the overall immune state during pregnancy plays a role leading to increased oral microbial load.

Besides the unclear mechanistic effect of pregnancy on the oral microbiota, the association between pregnancy and vaginal/oral microorganism carriage has revoked various discussions. For instance, one study revealed that oral microorganisms change during different stages of pregnancy. When comparing the abundance of seven common bacterial species in the oral cavity of nonpregnant women, early pregnancy, mid-pregnancy, and late pregnancy, the total viable microbial counts in all stages of pregnancy were higher than those of the nonpregnant women, especially in early pregnancy [51], and levels of the pathogenic bacteria Porphyromonas gingivalis and Aggregatibacter actinomycetemcomitans in the subgingival plaque, were significantly higher during the early and middle stages of pregnancy, compared to the non-pregnant group [51]. These results were further reinforced in an additional study, showing higher levels of A. actinomycetemcomitans and Candida in the second and third trimesters of pregnancy compared to nonpregnant women [53].

Fourth, we found that hypertension, decayed teeth number, and salivary $S$. mutans level are associated with oral Candida carriage in women, which have not been reported by previous studies. In recent years, with more research endeavors drawn to the association between oral Candida and tooth decay in children, research has indicated that children's oral Candida carriage is associated with $S$. mutans level, and decayed teeth number. The association between Candida and dental caries identified in the children's population might explain our findings in the adult population. This finding indeed intrigues an important clinical indication, which is restoring decayed teeth in mothers during pregnancy might offer therapeutic potential for controlling oral Candida in the mothers, preventing oral Candida colonization in infants by reducing the vertical transmission, and subsequently preventing dental caries in children.

Lastly, we examined the association between oral and vaginal C. albicans detection and indicated a high correlation, which is similar to some other study findings. Lockhart et al. [54] showed that among patients with recurrent vaginal candidiasis, $45 \%$ of them had identical oral and vulvovaginal isolates, $35 \%$ of them had related but not identical oral and vulvovaginal isolates, and $20 \%$ of them had unrelated oral and vulvovaginal isolates. The collective data from us and other studies indicated a cross-body sites contamination potential of C. albicans, between oral and vaginal habitats, which implies that the effective oral/vaginal Candida control strategy demands the consideration of both oral and vaginal origins.

The following limitations need to be considered when interpreting our study results: 1) With a cross-sectional study design, we only observed one time-point (the 3rd trimester) during the pregnancy and compared the oral 
condition and Candida carriage of the pregnant women to their non-pregnant counterparts. Although we observed that oral Candida detection is independent of the pregnancy, the results need to be confirmed by ideal study designs that examine all stages of pregnancy, including pre-, during, and post-pregnancy. 2) Limited sample size may have compromised the power of our multiple regression analyses. 3) The study was conducted in a single US city. Due to the nature of the single-site conducted study and small convenient sample size, the study results cannot be generalized to other populations. 4) The non-pregnant group was a convenience sample. The pregnant and non-pregnant subjects were enrolled from clinics where a majority of the patients are low-income individuals. The age and socioeconomic status were used to match the pregnant and non-pregnant groups. The status of holding New York state-support medical insurance was used as a filter for the selection of women with low socioeconomic status. The eligibility for state-support insurance is determined by income level ( $\leq 138 \%$ Federal Poverty Line). Although we did not conduct a case-by-case match for the education background, race, and ethnicity, there is no statistical difference in regard to the distribution of different races $(p=0.8)$ and ethnicity $(p=0.91)$ between the two groups (see Table 2). The current study focuses on the association, not causation, and we have controlled for the effects of covariates that might be potentially associated with the outcome variables in the models. We plan to match cases with controls using more variables and methods like propensity score in our future study.

\section{Conclusions}

Socioeconomically disadvantaged US women are in need of improved prenatal oral health, a large proportion of them have untreated decayed teeth and high prevalence and carriage of oral Candida. Study women's oral Candida carriage is positively associated with hypertension, decayed teeth number, and salivary $S$. mutans level. Due to the observed significant association between the decayed teeth number (caries severity) and oral Candida carriage, providing oral health care during pregnancy (including limit decayed teeth) will not only improve women's oral health, but also present as a promising approach to reduce oral Candida carriage in women, and subsequently benefit their offspring.

\section{Supplementary information}

Supplementary information accompanies this paper at https://doi.org/10. 1186/s12884-019-2618-7.

Additional file 1. Demographic and medical background

Additional file 2: Figure S1. Oral Candida status in non-pregnant mothers. (A) Oral (saliva and plaque) Candida species detection in non- pregnant women. (B). Candida species carriage in the saliva and plaque of non-pregnant women.

\section{Abbreviations}

CFU: Colony forming unit; Cl: Confidence interval; ECC: Early childhood caries; ElOH: Eastman Institute for Oral Health; HFM: Highland Family Medicine; MDFT: Decayed, Missing and Filled Teeth number; OR: Odds ratio

\section{Acknowledgments}

We thank the physicians, staff, and clinical administrative at the University of Rochester Highland Family Medicine for their generous support in recruiting study subjects and conducting study visits.

\section{Authors' contributions}

JX contributed to the conception, design, data acquisition, analysis, and interpretation, drafting and critically revising the manuscript; CF contributed to the conception, design, data interpretation, and critically reviewing the manuscript; TTW contributed to data acquisition, analysis, and interpretation, drafting and critically revising the manuscript; NA, YZ, MT, MY, LW, LC, HA and AN contributed to data acquisition, data interpretation and critically reviewing the manuscript. All authors have read and approved the final version of the manuscript and agree to be accountable for all aspects of the work.

\section{Funding}

Dr. Xiao's research was supported by the National Institute of Dental and Craniofacial Research grant K23DE027412. The funder of the study had no role in in the design of the study, collection, analysis, interpretation of data, and in writing the manuscript.

\section{Availability of data and materials}

The datasets generated and/or analysed during the current study are not publicly available due to individual privacy but are available from the corresponding author on reasonable request.

\section{Ethics approval and consent to participate}

The study protocols (RSRB00056870 and RSRB00067191) were approved by the University of Rochester Research subject review board. All participants were informed of the study objectives and protocols, and gave written consent prior to study activities.

Consent for publication

Not applicable.

\section{Competing interests}

The authors declare that they have no competing interests.

\section{Author details}

${ }^{1}$ Eastman Institute for Oral Health, University of Rochester Medical Center, 625 Elmwood Ave, Rochester, USA. ²Department of Family Medicine, University of Rochester Medical Center, Rochester, USA. ${ }^{3}$ Department of Biostatistics and Computational Biology, University of Rochester Medical Center, Rochester, USA. ${ }^{4}$ Department of Forensic Medicine, North Sichuan Medical College, Nanchong, China. ${ }^{5}$ College of Stomatology, Peking University, Beijing, China.

\section{Received: 8 February 2019 Accepted: 21 November 2019}

\section{References}

1. Corbella S, Taschieri S, Francetti L, De Siena F, Del Fabbro M. Periodontal disease as a risk factor for adverse pregnancy outcomes: a systematic review and meta-analysis of case-control studies. Odontology. 2012;100(2): 232-40.

2. Puertas A, Magan-Fernandez A, Blanc V, Revelles L, O'Valle F, Pozo E, Leon R, Mesa F. Association of periodontitis with preterm birth and low birth weight: a comprehensive review. J Matern Fetal Neonatal Med. 2018;31(5): 597-602.

3. Corbella S, Taschieri S, Del Fabbro M, Francetti $L$, Weinstein $R$, Ferrazzi E. Adverse pregnancy outcomes and periodontitis: a systematic review and 
meta-analysis exploring potential association. Quintessence Int. 2016;47(3): 193-204.

4. Merchant AT, Sutherland MW, Liu J, Pitiphat W, Dasanayake A. Periodontal treatment among mothers with mild to moderate periodontal disease and preterm birth: reanalysis of OPT trial data accounting for selective survival. Int J Epidemiol. 2018:47(5):1670-8.

5. Chaffee BW, Gansky SA, Weintraub JA, Featherstone JD, Ramos-Gomez FJ. Maternal oral bacterial levels predict early childhood caries development. J Dent Res. 2014;93(3):238-44.

6. Caufield PW, Li Y, Dasanayake A. Dental caries: an infectious and transmissible disease. Compend Contin Educ Dent. 2005;26(5 Suppl 1):10-6.

7. American Academy on Pediatric D, American Academy of P. Policy on early childhood caries (ECC): classifications, consequences, and preventive strategies. Pediatr Dent. 2008;30(7 Suppl):40-3.

8. Wakaguri S, Aida J, Osaka K, Morita M, Ando Y. Association between caregiver behaviours to prevent vertical transmission and dental caries in their 3-year-old children. Caries Res. 2011;45(3):281-6.

9. Twetman S. Prevention of dental caries as a non-communicable disease. Eur J Oral Sci. 2018;126(Suppl 1):19-25.

10. Tanzer JM. Dental caries is a transmissible infectious disease: the Keyes and Fitzgerald revolution. J Dent Res. 1995;74(9):1536-42.

11. Bowen WH. Dental caries - not just holes in teeth! A perspective. Mol Oral Microbiol. 2016;31(3):228-33.

12. Takahashi N, Nyvad B. The role of bacteria in the caries process: ecological perspectives. J Dent Res. 2011;90(3):294-303.

13. Kanasi E, Johansson I, Lu SC, Kressin NR, Nunn ME, Kent R Jr, Tanner AC. Microbial risk markers for childhood caries in pediatricians' offices. J Dent Res. 2010;89(4):378-83.

14. Caufield PW, Cutter GR, Dasanayake AP. Initial acquisition of mutans streptococci by infants: evidence for a discrete window of infectivity. J Dent Res. 1993;72(1):37-45.

15. Li Y, Caufield PW, Dasanayake AP, Wiener HW, Vermund SH. Mode of delivery and other maternal factors influence the acquisition of Streptococcus mutans in infants. J Dent Res. 2005;84(9):806-11.

16. Zhan L, Tan S, Den Besten P, Featherstone JD, Hoover Cl. Factors related to maternal transmission of mutans streptococci in high-risk children-pilot study. Pediatr Dent. 2012;34(4):e86-91.

17. Slayton RL. Reducing mutans streptococci levels in caregivers may reduce transmission to their children and lead to reduced caries prevalence. J Evid Based Dent Pract. 2011;11(1):27-8.

18. Klein MI, Florio FM, Pereira AC, Hofling JF, Goncalves RB. Longitudinal study of transmission, diversity, and stability of Streptococcus mutans and Streptococcus sobrinus genotypes in Brazilian nursery children. J Clin Microbiol. 2004:42(10):4620-6.

19. Klinke T, Urban M, Luck C, Hannig C, Kuhn M, Kramer N. Changes in Candida spp., mutans streptococci and lactobacilli following treatment of early childhood caries: a 1-year follow-up. Caries Res. 2014;48(1):24-31.

20. de Carvalho FG, Silva DS, Hebling J, Spolidorio LC, Spolidorio DM. Presence of mutans streptococci and Candida spp. in dental plaque/dentine of carious teeth and early childhood caries. Arch Oral Biol. 2006;51(11):1024-8.

21. Hossain H, Ansari F, Schulz-Weidner N, Wetzel WE, Chakraborty T, Domann E. Clonal identity of Candida albicans in the oral cavity and the gastrointestinal tract of pre-school children. Oral Microbiol Immunol. 2003;18(5):302-8.

22. Raja M, Hannan A, Ali K. Association of oral candidal carriage with dental caries in children. Caries Res. 2010:44(3):272-6.

23. Rozkiewicz D, Daniluk T, Zaremba ML, Cylwik-Rokicka D, Stokowska W, Pawinska M, Dabrowska E, Marczuk-Kolada G, Waszkiel D. Oral Candida albicans carriage in healthy preschool and school children. Adv Med Sci. 2006;51(Suppl 1):187-90.

24. Srivastava B, Bhatia HP, Chaudhary V, Aggarwal A, Kumar Singh A, Gupta N. Comparative evaluation of Oral Candida albicans carriage in children with and without dental caries: a microbiological in vivo study. Int J Clin Pediatr Dent. 2012;5(2):108-12.

25. Yang XQ, Zhang Q, Lu LY, Yang R, Liu Y, Zou J. Genotypic distribution of Candida albicans in dental biofilm of Chinese children associated with severe early childhood caries. Arch Oral Biol. 2012;57(8):1048-53.

26. Qiu R, Li W, Lin Y, Yu D, Zhao W. Genotypic diversity and cariogenicity of Candida albicans from children with early childhood caries and caries-free children. BMC Oral Health. 2015;15(1):144.

27. Al-Ahmad A, Auschill TM, Dakhel R, Wittmer A, Pelz K, Heumann C, Hellwig E, Arweiler NB. Prevalence of Candida albicans and Candida dubliniensis in caries-free and caries-active children in relation to the oral microbiota-a clinical study. Clin Oral Investig. 2016;20(8):1963-71.

28. Xiao J, Moon Y, Li L, Rustchenko E, Wakabayashi H, Zhao X, Feng C, Gill SR, McLaren S, Malmstrom $H$, et al. Candida albicans carriage in children with severe early childhood caries (S-ECC) and maternal relatedness. PLoS One. 2016;11(10):e0164242

29. Xiao J, Huang X, Alkhers N, Alzamil H, Alzoubi S, Wu TT, Castillo DA, Campbell F, Davis J, Herzog K, et al. Candida albicans and early childhood caries: a systematic review and meta-analysis. Caries Res. 2018;52(1-2):102-12.

30. Bliss JM, Basavegowda KP, Watson WJ, Sheikh AU, Ryan RM. Vertical and horizontal transmission of Candida albicans in very low birth weight infants using DNA fingerprinting techniques. Pediatr Infect Dis J. 2008;27(3):231-5.

31. Waggoner-Fountain LA, Walker MW, Hollis RJ, Pfaller MA, Ferguson JE, Wenzel RP, Donowitz LG. Vertical and horizontal transmission of unique Candida species to premature newborns. Clin Infect Dis. 1996;22(5):803-8.

32. Rocha JS, Arima LY, Werneck RI, Moyses SJ, Baldani MH. Determinants of dental care attendance during pregnancy: a systematic review. Caries Res. 2018;52(1-2):139-52.

33. Editorial. Majority of pregnant women have oral health problems, yet $43 \%$ don't seek dental treatment. In: Dentistry IQ; 2015.

34. Thompson TA, Cheng D, Strobino D. Dental cleaning before and during pregnancy among Maryland mothers. Matern Child Health J. 2013;17(1):110-8.

35. Marchi KS, Fisher-Owen SA, Weintraub JA, Yu Z, Braveman PA. Most pregnant women in California do not receive dental care: findings from a population-based study. Public Health Rep. 2010;125(6):831-42.

36. Singhal A, Chattopadhyay A, Garcia Al, Adams AB, Cheng D. Disparities in unmet dental need and dental care received by pregnant women in Maryland. Matern Child Health J. 2014;18(7):1658-66.

37. Guarnizo-Herreno CC, Wehby GL. Explaining racial/ethnic disparities in children's dental health: a decomposition analysis. Am J Public Health. 2012;102(5):859-66.

38. Azofeifa A, Yeung LF, Alverson CJ, Beltran-Aguilar E. Oral health conditions and dental visits among pregnant and nonpregnant women of childbearing age in the United States, National Health and nutrition examination survey, 1999-2004. Prev Chronic Dis. 2014;11:E163.

39. National Center for Health Statistics (US). Health US, 2017: With Special Feature on Mortality. In: Table 60, Untreated dental caries, by selected characteristics: United States, selected years 1988-1994 through 2011-2014. Hyattsville: National Center for Health Statistics (US); 2018. Available from: https://www.ncbi.nlm.nih.gov/books/NBK532684/table/ch4.tab60/.

40. Organization. WH. Oral health surveys - basic methods. 4th ed. Geneva: World Health Organization; 1997.

41. Loe H. The Gingival Index, the Plaque Index and the Retention Index Systems. J Periodontol. 1967;38(6):610-6.

42. Coronado-Castellote $\mathrm{L}$, Jimenez-Soriano Y. Clinical and microbiological diagnosis of oral candidiasis. J Clin Exp Dent. 2013;5(5):e279-86.

43. Odds FC, Bernaerts R. CHROMagar Candida, a new differential isolation medium for presumptive identification of clinically important Candida species. J Clin Microbiol. 1994;32(8):1923-9.

44. Little WA, Korts DC, Thomson LA, Bowen WH. Comparative recovery of Streptococcus mutans on ten isolation media. J Clin Microbiol. 1977;5(6):578-83.

45. Chen Z, Saxena D, Caufield PW, Ge Y, Wang M, Li Y. Development of species-specific primers for detection of Streptococcus mutans in mixed bacterial samples. FEMS Microbiol Lett. 2007;272(2):154-62.

46. Epstein JB, Pearsall NN, Truelove EL. Quantitative relationships between Candida albicans in saliva and the clinical status of human subjects. J Clin Microbiol. 1980;12(3):475-6.

47. Gold J, Tomar SL. Interdisciplinary community-based Oral health program for women and children at WIC. Matern Child Health J. 2018;22(11):1617-23.

48. Zomorodian K, Kavoosi F, Pishdad GR, Mehriar P, Ebrahimi H, Bandegani A, Pakshir K. Prevalence of oral Candida colonization in patients with diabetes mellitus. J Mycol Med. 2016;26(2):103-10.

49. Mun M, Yap T, Alnuaimi AD, Adams GG, McCullough MJ. Oral candidal carriage in asymptomatic patients. Aust Dent J. 2016;61(2):190-5.

50. Nowakowska D, Gaj Z, Nowakowska-Glab A, Wilczynski J. Occurrence of fungal infections in pregnant women and non-pregnant women with diabetes and without diabetes. Ginekol Pol. 2009;80(3):207-12.

51. Fujiwara N, Tsuruda K, Iwamoto Y, Kato F, Odaki T, Yamane N, Hori Y, Harashima Y, Sakoda A, Tagaya A, et al. Significant increase of oral bacteria in the early pregnancy period in Japanese wome. J Investig Clin Dent. 2017;8(1):e12189. 
52. Kumar PS. Sex and the subgingival microbiome: do female sex steroids affect periodontal bacteria? Periodontol 2000. 2013;61(1):103-24.

53. Borgo PV, Rodrigues VA, Feitosa AC, Xavier KC, Avila-Campos MJ. Association between periodontal condition and subgingival microbiota in women during pregnancy: a longitudinal study. J Appl Oral Sci. 2014;22(6): 528-33.

54. Lockhart SR, Reed BD, Pierson CL, Soll DR. Most frequent scenario for recurrent Candida vaginitis is strain maintenance with "substrain shuffling": demonstration by sequential DNA fingerprinting with probes $\mathrm{Ca} 3, \mathrm{C} 1$, and CARE2. J Clin Microbiol. 1996;34(4):767-77.

\section{Publisher's Note}

Springer Nature remains neutral with regard to jurisdictional claims in published maps and institutional affiliations.

Ready to submit your research? Choose BMC and benefit from:

- fast, convenient online submission

- thorough peer review by experienced researchers in your field

- rapid publication on acceptance

- support for research data, including large and complex data types

- gold Open Access which fosters wider collaboration and increased citations

- maximum visibility for your research: over $100 \mathrm{M}$ website views per year

At BMC, research is always in progress.

Learn more biomedcentral.com/submissions 